OPEN ACCESS

Edited by:

Nan Shen,

Shanghai Children's Medical

Center, China

Reviewed by:

Guillermo Soza,

University of La Frontera, Chile

Ana Beatriz Gorini Da Veiga,

Federal University of Health Sciences

of Porto Alegre, Brazil

${ }^{*}$ Correspondence:

Emma Carmelo

ecarmelo@ull.edu.es

Specialty section:

This article was submitted to

Pediatric Infectious Diseases,

a section of the journal

Frontiers in Pediatrics

Received: 28 May 2021 Accepted: 01 September 2021

Published: 28 September 2021

Citation:

Correia W, Dorta-Guerra $R$ Sanches M, Almeida Semedo CdJB, Valladares $B$, de Pina-Araújo IIM and

Carmelo E (2021) Study of the

Etiology of Acute Respiratory Infections in Children Under 5 Years at the Dr. Agostinho Neto Hospital, Praia,

Santiago Island, Cabo Verde.

Front. Pediatr. 9:716351

doi: 10.3389/fped.2021.716351

\section{Study of the Etiology of Acute Respiratory Infections in Children Under 5 Years at the Dr. Agostinho Neto Hospital, Praia, Santiago Island, Cabo Verde}

\author{
Wilson Correia ${ }^{1}$, Roberto Dorta-Guerra ${ }^{1,2}$, Mitza Sanches ${ }^{3}$, \\ Carmen de Jesús Borges Almeida Semedo ${ }^{3}$, Basilio Valladares ${ }^{1,4}$, \\ Isabel Inês M. de Pina-Araújo ${ }^{5}$ and Emma Carmelo ${ }^{1,4,6 *}$
}

${ }^{1}$ Instituto Universitario de Enfermedades Tropicales y Salud Pública de Canarias, Universidad de La Laguna, La Laguna, Spain, ${ }^{2}$ Departamento de Matemáticas, Estadística e Investigación Operativa, Facultad de Ciencias, Universidad de La Laguna, La Laguna, Spain, ${ }^{3}$ Hospital Dr. Agostinho Neto, Ministry of Health and Social Security of Cabo Verde, Praia, Cabo Verde, ${ }^{4}$ Departamento de Obstetricia y Ginecología, Pediatría, Medicina Preventiva y Salud Pública, Toxicología, Medicina Legal y Forense y Parasitología, Universidad de La Laguna, La Laguna, Spain, ${ }^{5}$ Faculty of Sciences and Technology, University of Cabo Verde, Praia, Cabo Verde, ${ }^{6}$ Red de Investigación Colaborativa en Enfermedades Tropicales (RICET), Madrid, Spain

Background: Acute respiratory infections are one of the major causes of morbidity and mortality in children under 5 years in developing countries and are a challenge for the health system of these countries. In Cabo Verde, despite the lack of recent studies, data indicate that it affects thousands of children, being the fourth leading cause of infant mortality in 2013. The aim of this study was to identify and describe the etiological agents associated with acute respiratory tract infections in children under 5 years old, and their associated risk factors, such as clinical symptoms or socio-demographic characteristics.

Methods: Naso-pharyngeal samples were collected from children under 5 years attending at Dr. Agostinho Neto Hospital (Praia, Santiago Island, Cabo Verde) with suspected ARI at different time-points during 2019. Samples were analyzed using FilmArray Respiratory Panel v. 2.0 Plus to identify etiological agents of ARI. A questionnaire with socio-demographic information was also collected for each participant. Data analyses were carried out using the IBM SPSS version 25 (IBM Corporation, Armonk, NY) and R 3.5.1 statistical software.

Results: A total of 129 naso-pharyngeal samples were included in the study. Seventeen different etiologic agents of respiratory infections were identified. HRV/EV was the most frequent agent detected, followed by FluA H3 and RSV. Coinfection with two or more pathogens was detected in up to $20 \%$ of positive samples. The results were analyzed in terms of age-group, sex, period of the year and other social and demographic factors.

Conclusion: Viruses are the main causative agents of ARI in children $<5$ years attending at the pediatrics service at the Dr. Agostinho Neto Hospital in Praia city, Santiago Island, Cabo Verde. Some factors are described in this study as statistically associated with 
the presence of an infectious agent, such as having one or more children sharing the bedroom with an adult and the presence of some clinical symptoms. The data addresses the need for studies on respiratory tract infections in Cabo Verde.

Keywords: children, acute respiratory infections, ARI, molecular diagnostics, FilmArray, Cabo Verde, pediatric infections

\section{INTRODUCTION}

Acute respiratory infections (ARI) are defined as infections in the respiratory tract (lower and/or upper), resulting in obstruction of the air passage at the nasal and/or bronchial system, causing a spectrum of manifestations, from acute symptoms, like common colds, to more serious conditions such as pneumonia or lung collapse (1). ARI often constitutes a medical emergency, because it directly affects tissue oxygenation, driving to complications in children, with poor outcomes including increased morbidity and mortality. It is not uncommon that ARI requires intensive care, permanent evaluation, as well as quick and resolutive interventions $(2,3)$.

Despite the usually benign nature of the infection, ARI is an enormous economic burden on society in terms of visits to doctors and other health-care providers, treatments, and absences from work, school and/or day care (4).

Among ARI, infections of the upper respiratory tract are the most frequent, but the majority of respiratory deaths are attributed to acute lower respiratory infections $(5,6)$. Both bacteria and viruses have been identified as the agents of ARI, however, it is known that $90 \%$ of these infections have viral origin $(2,7)$. In children with ARI, respiratory syncytial virus (RSV), influenza virus types $A$ and $B$ (Flu $A$ and Flu B), adenovirus (ADV), parainfluenza virus (PIV), human metapneumovirus (hMPV) and human rhinovirus/enterovirus $(\mathrm{HRV} / \mathrm{EV})$ are the most frequently detected viruses $(7,8)$. Other viruses such as human bocavirus (hBoVs), and mainly severe acute respiratory syndrome coronavirus (SARS-CoV), middle east respiratory syndrome coronavirus (MERS-CoV), and more recently a new type of coronavirus (SARS-CoV-2), the

\footnotetext{
Abbreviations: RICET, Red de Investigación Colaborativa en Enfermidades Tropicales; ARI, Acute Respiratory infection; ADV, Adenovirus; CoV 229E, Coronavirus 229E; CoV HKU1, Coronavirus HKU1; CoV OC43, Coronavirus OC43; CoV NL63, Coronavirus NL63; HRV/EV, Human Rhinovirus/Enterovirus; hMPV, Human Metapneumovirus; FluA, Influenza A; Flu A H1 2009, Influenza A H1 2009; Flu A H3, Influenza A H3; Flu A H1, Influenza A H1, Flu B, Influenza B; PIV 1, Parainfluenza Virus 1; PIV 2, Parainfluenza Virus 2; PIV 3, Parainfluenza Virus 3; PIV 4, Parainfluenza Virus 4; RSV, Syncytial Respiratory Virus; MERS-CoV, Middle East Respiratory Syndrome; SARS-CoV, Severe Acute Respiratory Syndrome Coronavirus; SARS-CoV-2, Severe Acute Respiratory Syndrome Coronavirus 2; hBoVs, Human bocavirus; C. pneumoniae, Chlamydia pneumoniae, M. pneumoniae, Mycoplasma pneumoniae; OSMF, OpenStreetMap Foundation; NPS, Naso-pharyngeal; VTM, Viral Transport Medium; IUETSPC/ULL, Instituto Universitario de Enfermedades Tropicales y Salud Pública de Canarias, Universidad de La Laguna; PCR, Polymerase Chain Reaction; FARP, FilmArray ${ }^{\circledR}$ Respiratory Panel; COR, Crude odds ratios; AOR, Adjusted odds ratios; CAP, Community-acquired pneumonia; CoVs, Acute Several Coronavirus; CNEPS, National Health Research Ethics Committee of Cabo Verde; FUNCCET, Fundación Canarias para el Control de Enfermidades Tropicales; INSP, National Institute of Public Health of Cabo Verde.
}

causative agent of COVID-19 respiratory infection worldwide, have been described as responsible for more severe symptoms like respiratory distress syndrome $(9,10)$. Bacteria such as Streptococcus pneumoniae, Staphylococcus aureus and Klebsiella pneumoniae are less frequently reported $(6,7,11)$.

The clinical manifestations of respiratory infections caused by these agents are similar in most cases, including cough, fever $\geq 38^{\circ} \mathrm{C}$, headache and/or difficult breathing, among others. On the other hand, the clinical spectrum is variable, ranging from mild infections, which can be treated on an outpatient basis, to more serious forms that require hospitalization, particularly in patients with cardiopathy or metabolic diseases $(6,12-15)$. The early detection of the potential causative agents of ARI is essential for appropriate treatment, helping to reduce the overuse of antibiotics therapy, and prevent outbreaks or reinfection. In this context, polymerase chain reaction (PCR) assays have shown to be a sensitive and specific tool for detection of these agents, particularly the multiplex-PCR assays, enabling the detection of multiple targets in a single clinical specimen (9).

ARI are the main cause of morbidity and mortality worldwide, especially in children under 5 years (7). It is responsible for more than 12 million hospital admissions and 1.9 to 2.2 million deaths in children each year, 70\% occurring in Africa and Southeast Asia $(6,16,17)$. Studies show that the etiological agents of ARIs are geographically diverse and are associated with the epidemic status of each ARIs and climate conditions (18). Therefore, data on the epidemiology of ARI cases are very important to develop control and prevention strategies (11).

Archipelago of Cabo Verde is located off the West African coast, $500 \mathrm{~km}$ away from Senegal. With a total of $4,033 \mathrm{~km}^{2}$ and 544,081 residents, Cabo Verde has a young population, with $47 \%$ of people under 24 years-old and only $6 \%$ of over 65 years old $(19,20)$. Cabo Verde is facing demographic and epidemiological changes, as well as an increasingly demanding population. The country needs to address "old" challenges, such as controlling transmissible diseases, and at the same time tackle emerging needs such as responding to the increasing prevalence of nontransmissible diseases. To keep control of this challenges, the country has provided a new national health plan, the National Health Development Plan 2017-2021, including 8 strategies of development and operational initiatives to improve the health of the population of Cabo Verde (20).

According to WHO, in 2013 ARI was considered the fourth cause of mortality in children under 5 years in Cabo Verde (21). Between 2014 and 2018, ARI was the condition showing the highest notification in children under 5 years with an average of 31,238 cases per year (22). Despite the high notification rate, there is little scientific literature describing the etiological agents of ARI and the associated risk factors in Cabo Verde. Only one research 


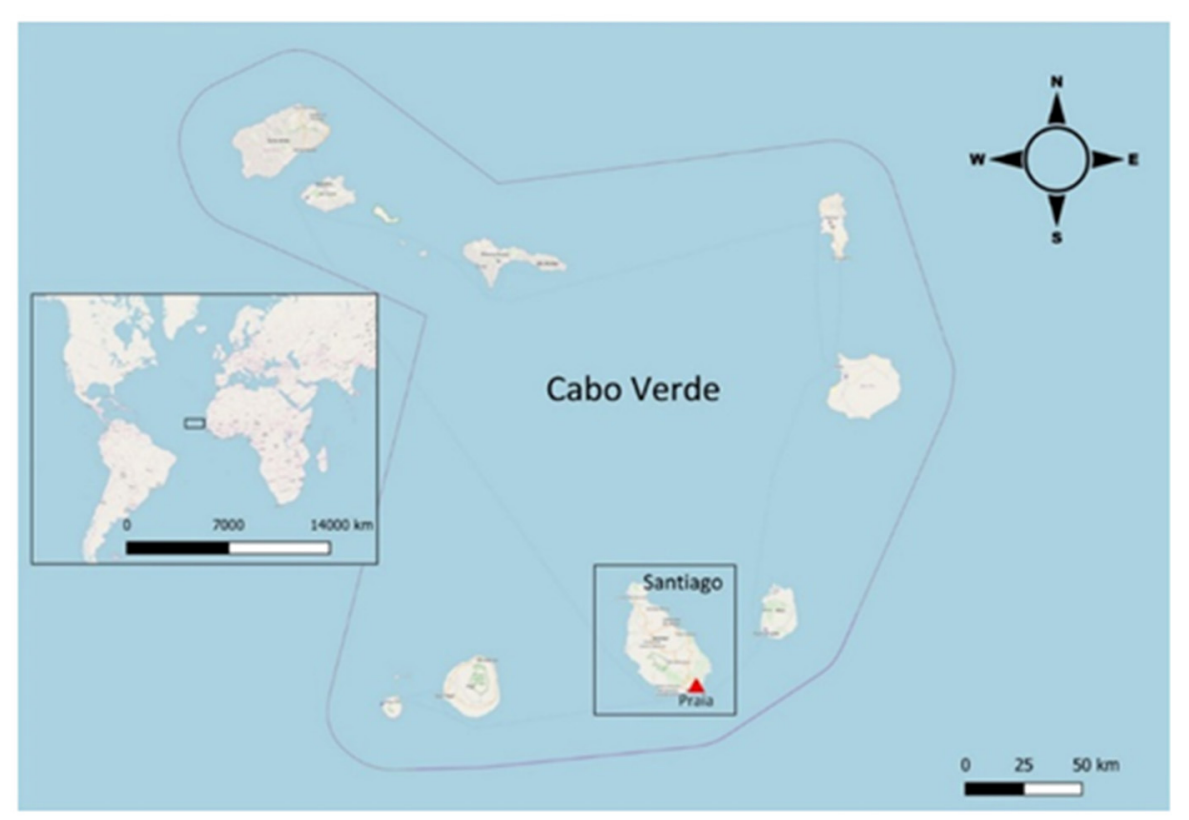

FIGURE 1 | Location of Praia in Santiago Island (Cabo Verde). Map modified with QGIS 3.8.0-Zanzibar (www.qgis.org) from OpenStreetMap.org. OpenStreetMap® is open data, licensed under the Open Data Commons Open Database License (ODbL) by the OpenStreetMap Foundation (OSMF).

project was conducted between 2009 and 2010 in Senegal, Cabo Verde, Mauritania and Guinea, revealing the involvement of the influenza virus A and B in complications of the respiratory tract in samples collected from patients seeking health care in those countries (23). Of 3,155 samples tested, 911 (28.9\%) were positive for influenza virus, with influenza A being the most prevalent virus detected, and patients aged between 5 and 14 years and $<5$ years were the most affected $(72 / 422,17.1 \% ; 262 / 1642 ; 16.2 \%$, respectively) (23).

Determining the etiological agents of ARI in Cabo Verde is fundamental not only for surveillance, for diagnostic and therapeutic purposes, but also to illustrate the relationships between ARI in children and local demographic, socioeconomic and environmental factors, in order to contribute to defining public health policies regarding ARI. The aim of this study was to identify the etiological agents associated with acute respiratory tract infections in children under 5 years at Dr. Agostinho Neto Hospital (Praia, Santiago Island, Cabo Verde) and the clinical symptoms associated with this infection. In parallel, the distribution of ARI by age, sex, season, geographic location and their associated risk factors was described.

\section{MATERIALS AND METHODS \\ Study Design and Data Collection}

We collected cross-sectional data in January, May and November 2019 of children under 5 years of age attended at the Pediatrics' emergency and ambulatory service at Hospital Dr. Agostinho Neto (HAN) in Praia city, Santiago Island, Archipelago of Cabo Verde with suspected acute respiratory infection (ARI) (Figure 1).
To be included in the study, children were identified by clinicians and must have had three or more typical symptoms of ARI (cough, nasal obstruction, chest pain, headache, difficult breathing, conjunctivitis and/or fever $\geq 38^{\circ} \mathrm{C}$ ), starting at least 3-7 days before, and not under any treatment.

These inclusion criteria were defined by Fitzner et al. (15). In some cases, according to medical recommendations, children with less than three typical symptoms of ARI were included in the study.

All samples were accompanied by a questionnaire, containing child socio-demographic and clinical data provided by the assisting medical professionals as well as parents and/or guardian. Specimens were naso-pharyngeal swabs (NPS) collected in $3 \mathrm{ml}$ of Viral Transport Medium (VTM) (Delta lab, Barcelona, Spain), according to Baden et al. (24). Samples were stored at $-80^{\circ} \mathrm{C}$ until transport to the laboratory of the Instituto Universitario de Enfermedades Tropicales y Salud Pública de Canarias, Universidad de La Laguna (IUETSPC/ULL) in Tenerife, Canary Islands.

\section{FilmArray Testing}

The detection of the virus and bacteria considered etiological agents of ARI was performed using FilmArray ${ }^{\circledR}$ Respiratory Panel v.2.0 Plus (FARP-FilmArray ${ }^{\circledR}$ Respiratory Panel BioFire Diagnostics LLC 390; Wakara Way Salt Lake City, UT, USA). FilmArray RP2plus is a test based on multiplex PCR (25) designed for the simultaneous detection and identification of nucleic acids of 18 respiratory viruses and 4 bacteria (26). The viruses are Adenovirus (ADV), Coronavirus 229E (CoV 229E), Coronavirus HKU1 (CoV HKU1), Coronavirus OC43 (CoV OC43), Coronavirus NL63 (CoV NL63), Human 
TABLE 1 | Frequency (\%) of respiratory pathogens by age, sex, study period and geographic areas in Praia, during 2019.

\begin{tabular}{|c|c|c|c|c|c|c|c|c|c|c|c|c|c|c|c|c|c|c|}
\hline \multirow[b]{2}{*}{ Pathogen } & \multicolumn{2}{|c|}{ Prevalences } & \multicolumn{3}{|c|}{ Age, $+/$ n (\%) } & \multicolumn{3}{|c|}{ Sex, + /n (\%) } & \multicolumn{4}{|c|}{ Study Period, $+/ \mathrm{n}(\%)$} & \multicolumn{6}{|c|}{ Geographic areas in Praia, $+/ n(\%)$} \\
\hline & $+/ \mathrm{n}(\%)$ & (95\% Cl) & $<1$ year & $1-4$ years & Sig. & Female & Male & Sig. & January & May & November & Sig. & North & West & South & East & Other & Sig. \\
\hline ADV & 12/129 (9.3) & $(4.9-15.7)$ & $6 / 60(10.0)$ & $6 / 69(8.7)$ & n.s. & $9 / 62(14.5)$ & $3 / 67(4.5)$ & n.s. & 2/35 (5.7) & 6/46 (13.0) & $4 / 48(8.3)$ & n.s. & 4/31 (12.9) & 3/22 (13.6) & $2 / 44(4.5)$ & 2/17 (11.8) & $0 / 13(0.0)$ & ) n.s. \\
\hline CoV 229E & $1 / 129(0.8)$ & $(0.0-4.2)$ & $1 / 60(1.7)$ & 0/69 (0.0) & n.s. & 0/62 (0.0) & $1 / 67(1.5)$ & n.s. & $1 / 35(2.9)$ & 0/46 (0.0) & $0 / 48(0.0)$ & n.s. & $0 / 31(0.0)$ & $0 / 22(0.0)$ & 0/44 (0.0) & $0 / 17(0.0)$ & $0 / 13(0.0)$ & ) n.s. \\
\hline CoV HKU1 & 1/129 (0.8) & $(0.0-4.2)$ & $1 / 60(1.7)$ & $0 / 69(0.0)$ & n.s. & 1/62 (1.6) & 0/67 (0.0) & n.s. & 0/35 (0.0) & $1 / 46(2.2)$ & $0 / 48(0.0)$ & n.s. & 0/31 (0.0) & 1/22 (4.5) & 0/44 (0.0) & 0/17 (0.0) & 0/13 (0.0) & n.s. \\
\hline CoV OC43 & $4 / 129(3.1)$ & $(0.9-7.7)$ & 2/60 (3.3) & 2/69 (2.9) & n.s. & 1/62 (1.6) & $3 / 67(4.5)$ & n.s. & $1 / 35(2.9)$ & $2 / 46(4.3)$ & $1 / 48(2.1)$ & n.s. & $2 / 31(6.5)$ & $0 / 22(0.0)$ & $1 / 44(2.3)$ & $0 / 17(0.0)$ & $1 / 13(7.7)$ & n.s. \\
\hline CoV NL63 & $2 / 129(1.6)$ & $(0.2-5.5)$ & $1 / 60(1.7)$ & $1 / 69(1.4)$ & n.s. & 0/62 (0.0) & 2/67 (3.0) & n.s. & 0/35 (0.0) & 0/46 (0.0) & $2 / 48(4.2)$ & n.s. & 1/31 (3.2) & 0/22 (0.0) & 0/44 (0.0) & 0/17 (0.0) & $1 / 13(7.7)$ & n.s. \\
\hline HRV/EV & $51 / 129(39.5)$ & (31.0-48.5) & $28 / 60(46.7)$ & ) 23/69 (33.3) & n.s. & $25 / 62(40.3)$ & $26 / 67(38.8)$ & n.s. & $9 / 35(25.7)$ & $24 / 46(52.2)$ & ) $18 / 48(37.5)$ & n.s. & $11 / 31(35.5)$ & $10 / 22(45.5)$ & $19 / 44(43.2)$ & 6/17 (35.3) & $4 / 13(30.8)$ & B) n.s. \\
\hline hMPV & $9 / 129(7.0)$ & $(3.2-12.8)$ & 6/60 (10.0) & 3/69 (4.3) & n.s. & 4/62 (6.5) & $5 / 67(7.5)$ & n.s. & 1/35 (2.9) & $8 / 46(17.4)$ & 0/48 (0.0) & 0.001 & $3 / 31(9.7)$ & 1/22 (4.5) & 2/44 (4.5) & 1/17 (5.9) & 2/13 (15.4) & 4) n.s. \\
\hline RSV & $13 / 129(10.1)$ & $(5.5-16.6)$ & 6/60 (10.0) & $7 / 69(10.1)$ & n.s. & 7/62 (11.3) & $6 / 67(9.0)$ & n.s. & 0/35 (0.0) & $1 / 46(2.2)$ & $12 / 48(25.0)$ & $<0.001$ & 4/31 (12.9) & 2/22 (9.1) & $3 / 44(6.8)$ & 2/17 (11.8) & $1 / 13(7.7)$ & n.s. \\
\hline $\begin{array}{l}\text { FluA } \\
\text { H1-2009 }\end{array}$ & 1/129 (0.8) & $(0.0-4.2)$ & $1 / 60(1.7)$ & 0/69 (0.0) & n.s. & 1/62 (1.6) & 0/67 (0.0) & n.s. & $1 / 35(2.9)$ & 0/46 (0.0) & 0/48 (0.0) & n.s. & 0/31 (0.0) & 1/22 (4.5) & 0/44 (0.0) & 0/17 (0.0) & $0 / 13(0.0)$ & ) n.s. \\
\hline FluA H3 & $18 / 129(14.0)$ & $(8.5-21.2)$ & $4 / 60(6.7)$ & 14/69 (20.3) c & 0.049 & 8/62 (12.9) & $10 / 67(14.9)$ & n.s. & 6/35 (17.1) & 0/46 (0.0) & $12 / 48(25.0)$ & $<0.001$ & 6/31 (19.4) & 1/22 (4.5) & 8/44 (18.2) & 2/17 (11.8) & $1 / 13(7.7)$ & n.s. \\
\hline FluB & $4 / 129(3.1)$ & $(0.9-7.7)$ & 1/60 (1.7) & 3/69 (4.3) & n.s. & 1/62 (1.6) & $3 / 67$ (4.5) & n.s. & 0/35 (0.0) & 0/46 (0.0) & 4/48 (8.3) & 0.037 & $1 / 31(3.2)$ & 0/22 (0.0) & $3 / 44$ (6.8) & 0/17 (0.0) & 0/13 (0.0) & n.s. \\
\hline PIV 1 & $1 / 129(0.8)$ & $(0.0-4.2)$ & 0/60 (0.0) & $1 / 69(1.4)$ & n.s. & 1/62 (1.6) & 0/67 (0.0) & n.s. & $1 / 35(2.9)$ & 0/46 (0.0) & $0 / 48(0.0)$ & n.s. & $0 / 31(0.0)$ & 0/22 (0.0) & 0/44 (0.0) & $1 / 17$ (5.9) & 0/13 (0.0) & n.s. \\
\hline PIV 2 & $1 / 129(0.8)$ & $(0.0-4.2)$ & 1/60 (1.7) & 0/69 (0.0) & n.s. & 0/62 (0.0) & 1/67 (1.5) & n.s. & 1/35 (2.9) & 0/46 (0.0) & 0/48 (0.0) & n.s. & $0 / 31(0.0)$ & 0/22 (0.0) & $1 / 44(2.3)$ & 0/17 (0.0) & 0/13 (0.0) & n.s. \\
\hline PIV 3 & $3 / 129(2.3)$ & $(0.5-6.6)$ & $3 / 60(5.0)$ & 0/69 (0.0) & n.s. & 2/62 (3.2) & 1/67 (1.5) & n.s. & $2 / 35(5.7)$ & $1 / 46(2.2)$ & $0 / 48(0.0)$ & n.s. & $1 / 31(3.2)$ & $1 / 22(4.5)$ & $1 / 44(2.3)$ & 0/17 (0.0) & 0/13 (0.0) & n.s. \\
\hline PIV 4 & 1/129 (0.8) & $(0.0-4.2)$ & 0/60 (0.0) & $1 / 69(1.4)$ & n.s. & 1/62 (1.6) & 0/67 (0.0) & n.s. & 0/35 (0.0) & 0/46 (0.0) & $1 / 48(2.1)$ & n.s. & $0 / 31(0.0)$ & 0/22 (0.0) & 0/44 (0.0) & 0/17 (0.0) & $1 / 13(7.7)$ & n.s. \\
\hline $\begin{array}{l}\text { C. } \\
\text { pneumoniae }\end{array}$ & $3 / 129(2.3)$ & $(0.5-6.6)$ & $1 / 60(1.7)$ & 2/69 (2.9) & n.s. & 0/62 (0.0) & $3 / 67(4.5)$ & n.s. & 0/35 (0.0) & 2/46 (4.3) & $1 / 48(2.1)$ & n.s. & 1/31 (3.2) & $1 / 22(4.5)$ & $1 / 44(2.3)$ & 0/17 (0.0) & 0/13 (0.0) & ) n.s. \\
\hline $\begin{array}{l}\text { M. } \\
\text { pneumoniae }\end{array}$ & $1 / 129(0.8)$ & $(0.0-4.2)$ & 0/60 (0.0) & $1 / 69(1.4)$ & n.s. & 0/62 (0.0) & 1/67 (1.5) & n.s. & 0/35 (0.0) & 1/46 (2.2) & $0 / 48(0.0)$ & n.s. & $1 / 31(3.2)$ & 0/22 (0.0) & 0/44 (0.0) & 0/17 (0.0) & 0/13 (0.0) & ) n.s. \\
\hline $\begin{array}{l}\geq 1 \\
\text { pathogen }\end{array}$ & $102 / 129(79.1)$ & $(71.0-85.7)$ & $51 / 60(85.0)$ & ) 51/69 (73.9) & n.s. & 49/62 (79.0) & 53/67 (79.1 & n.s. & 23/35 (65.7) & ) 36/46 (78.3) & ) 43/48 (89.6) & 0.030 & $/ 31(87.1)$ & 16/22 (72 & $3 / 44$ & $13 / 1$ & ) $8 / 13(6$ & 5) n.s. \\
\hline
\end{tabular}

ADV, Adenovirus; CoV 229E, Coronavirus 229E; CoV HKU1, Coronavirus HKU1; CoV OC43, Coronavirus OC43; CoV NL63, Coronavirus NL63; HRV/EV, Human Rhinovirus/Enterovirus; hMPV, Human Metapneumovirus; RSV, Respiratory Syncytial Virus; FluA H1 2009, Influenza A H1 2009; FluA H3, Influenza A H3; FluB, Influenza B; PIV 1, Parainfluenza virus 1; PIV 2, Parainfluenza Virus 2; PIV 3, Parainflueza Virus3; PIV 4, Parainfluenza Virus 4; C. pneumoniae, Chamydophila pneumoniae; M. pneumoniae, Mycoplasma pneumoniae. 
Rhinovirus/Enterovirus (HRV/EV), Human Metapneumovirus (hMPV), Influenza A (FluA), Influenza A H1 2009 (Flu A H1 2009), Influenza A H3 (Flu A H3), Influenza A H1 (Flu A H1), Influenza B (Flu B), Parainfluenza Virus 1 (PIV 1), Parainfluenza Virus 2 (PIV 2), Parainfluenza Virus 3 (PIV 3), Parainfluenza Virus 4 (PIV 4), Respiratory Syncytial Virus (RSV), and Middle East Respiratory Syndrome (MERS$\mathrm{CoV}$ ). The bacteria are Chlamydophila pneumoniae, Mycoplasma pneumoniae, Bordetella parapertussis and Bordetella pertussis $(26,27)$. A fraction of $300 \mu \mathrm{l}$ of each sample was subjected to FilmArray RP2plus testing according to the manufacturer's instructions (available in: www.biofiredx.com).

\section{Statistical Analysis}

Data analyses were carried out using the IBM SPSS version 25 (IBM Corporation, Armonk, NY) and R 3.5.1 statistical software. Results are presented as means \pm standard deviations (SD) for continuous data and proportions (prevalence) for categorical data. Ninety-five percent confidence intervals for prevalence using the approximate or exact method, as appropriate, were included.

Chi-square test or Fisher's exact test, as appropriate, were assessed to study the associations between the presence of pathogens and some sociodemographic variables. Results with $p<0.05$ were considered statistically significant. To determine predictor variables for ARI, a binary logistic regression model was fitted and variables at a $p<0.2$ during the bi-variate analysis were included in the multivariable analysis. All assumptions for binary logistic regression were checked. Finally, variables found to be significant at a $p<0.05$ in the final model were declared as predictors. Crude odds ratios (COR) and adjusted odds ratios (AOR) with 95\% confidence interval were reported. Hosmer and Lemeshow goodness-of-fit test $(p>0.05)$ was used to check model fitness.

\section{RESULTS}

\section{Demographic Characteristics}

A total of 129 naso-pharyngeal swabs from children $<5$ years old with suspected ARI were collected and analyzed during the study period. In detail, $60(46.5 \%)$ of them belong to children $<1$ years of age and $69(53.5 \%)$ between 1 and 4 years old. The sex distribution was $62(48.1 \%)$ female and 67 (51.9\%) male samples. Sampling was performed in three different periods in 2019, 35 (27.1\%) in January, 46 (35.7\%) in May and 48 (37.2\%) in November. Most of the patients $(88.4 \%, 114 / 129)$ came from Praia city, and in two patients this information is lacking (Table 1). According to the clinical signs and symptoms, most patients enrolled in this study presented with nasal obstruction $(119,92.2 \%)$, cough $(112,86.9 \%)$ and fever $\geq 38^{\circ} \mathrm{C}(84,65.1 \%)$. Difficult breathing $(28,21.7 \%)$, conjunctivitis $(6,4.7 \%)$, chest pain $(4,3.1 \%)$, and headache $(3,2.3 \%)$ were also reported. A total of $63(48.8 \%)$ patients enrolled in this study presented the first symptoms between 6 and 7 days before attending HAN, 40 (31.0\%) at 3-5 days and $26(20.2 \%)$ presented first symptoms 12 days before seeking medical attention. Most $(88.4 \%, 114 / 129)$ of the children lived in Praia, the capital city of Santiago Island
TABLE 2 | Reported cases of respiratory pathogens co-infection in the study population.

\begin{tabular}{|c|c|c|}
\hline Presentation & & $+/ \mathrm{n}(\%)$ \\
\hline Single pathogens infection & & $81 / 102(79.4)$ \\
\hline Co-infection & & $21 / 102$ (20.6) \\
\hline \multirow[t]{12}{*}{2 pathogens } & $\mathrm{ADV}+\mathrm{HRV} / \mathrm{EV}$ & 6/21 (28.5) \\
\hline & $\mathrm{HRV} / \mathrm{EV}+\mathrm{RSV}$ & 4/21 (19.0) \\
\hline & ADV+CoV HKU1 & $1 / 21(4.7)$ \\
\hline & $\mathrm{ADV}+\mathrm{hMPV}$ & $1 / 21(4.7)$ \\
\hline & $\mathrm{ADV}+\mathrm{RSV}$ & $1 / 21(4.7)$ \\
\hline & CoV OC43+HRV/EV & $1 / 21(4.7)$ \\
\hline & CoV OC43+CoV NL63 & $1 / 21(4.7)$ \\
\hline & FluA H3+ C. pneumoniae & $1 / 21(4.7)$ \\
\hline & $\mathrm{HRV} / \mathrm{EV}+$ FluA H3 & $1 / 21(4.7)$ \\
\hline & HRV/EV+hMPV & $1 / 21(4.7)$ \\
\hline & HRV/EV+PIV 3 & $1 / 21(4.7)$ \\
\hline & C. pneumoniae+M. pneumoniae & $1 / 21(4.7)$ \\
\hline 3 pathogens & $\mathrm{ADV}+\mathrm{HRV} / \mathrm{EV}+\mathrm{RVS}$ & $1 / 21(4.7)$ \\
\hline
\end{tabular}

ADV, Adenovirus; CoV HKU1, Coronavirus HKU1; CoV OC43, Coronavirus OC43; CoV NL63, Coronavirus NL63; HRV/EV, Human Rhinovirus/Enterovirus; hMPV, Human Metapneumovirus; RSV, Respiratory Syncytial Virus; FluA H3, Influenza A H3; PIV 3, Parainfluenza Virus 3; C. pneumoniae, Chamydophila pneumoniae; M. pneumoniae, Mycoplasma pneumoniae.

that can be divided in 4 geographic areas: North of Praia, West of Praia, South of Praia, and East of Praia. Positive samples were distributed among all areas, showing no clear geographical pattern (Table 1).

\section{Respiratory Pathogens Causing ARI in Children Under 5 Years Old in Cabo Verde}

Among the 129 naso-pharyngeal samples tested, $102(79.1 \%)$ were positive for one or more of the pathogens detected in the Panel. HRV/EV was the most frequent respiratory pathogen (39.5\%), followed by FluA H3 (14.0\%) and RSV (10.1\%; Table 1). The detection rates for all other pathogens tested were below $10 \%$ (Table 1). A single respiratory pathogen was detected in 81 $(62.8 \%)$ positive samples, and multiple pathogens were detected in 21 of them (20.6\%; Table 2$)$, generally combinations of HRV/EV (14/21, 66.6\%), ADV (10/21, 47.6\%), or RSV (6/21, $28.5 \%$ ) with a different infectious agent (Figure 2, Table 2).

The combination of three respiratory pathogens was found in a single sample, representing $4.8 \%$ of co-infections. The most frequent finding in terms of co-infection was ADV $+\mathrm{HRV} / \mathrm{EV}$ viruses, with six cases (28.5\%), followed by HRV/EV + RSV (19.0\%; Table 2).

Age clustering revealed a balanced positivity rate, with $85.0 \%$ positives in the $<1$ year old age group and $73.9 \%$ in the $1-4$ years old (Table 1). Besides, most pathogens were detected at similar rates in both age groups. In contrast, FluA H 3 was most prevalent in the 1-4 year old group ( $p=0.049$, Table 1 ), suggesting an influence of age for this infection. Regarding sex, no statistically significant differences were observed between boys' and girls' infection rates (Table 1). It is interesting the higher frequency 


\section{Respiratory pathogens}

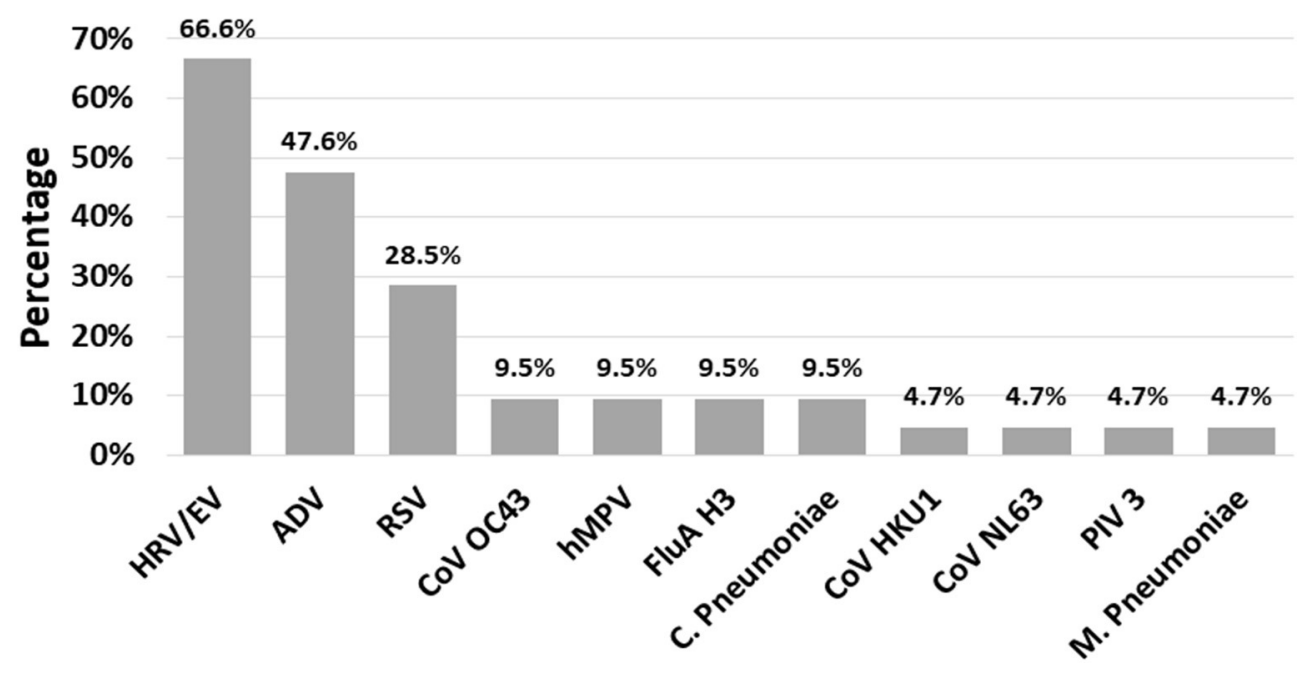

FIGURE 2 | The frequency (\%) of each respiratory pathogen in the context of a co-infection. ADV, Adenovirus; CoV HKU1, Coronavirus HKU1; CoV OC43, Coronavirus OC43; CoV NL63, Coronavirus NL63; HRV/EV, Human Rhinovirus/Enterovirus; hMPV, Human Metapneumovirus; RSV, Respiratory Syncytial Virus; FluA H3, Influenza A H3; PIV 3, Parainflueza Virus 3; C. Pneumoniae, Chamydophila pneumoniae; M. Pneumoniae, Mycoplasma pneumoniae.

TABLE 3 | Relation between Symptoms and ARI.

\begin{tabular}{|c|c|c|c|c|c|c|}
\hline & & ARI negative -/n (\%) & ARI positive +/n (\%) & COR (95\% Cl) & $p$-value & AOR $(95 \% \mathrm{Cl})$ \\
\hline \multirow[t]{3}{*}{ Time from first Symptoms } & 1-2 days & $3 / 26(11.5)$ & 23/26 (88.5) & & & \\
\hline & $3-5$ days & $5 / 40(12.5)$ & $35 / 40(87.5)$ & $0.91(0.20-4.20)$ & 0.91 & - \\
\hline & $6-7$ days & 19/63 (30.2) & 44/63 (69.8) & $0.30(0.08-1.13)$ & 0.08 & - \\
\hline \multirow[t]{2}{*}{ Nasal obstruction } & Absent & $6 / 10(60.0)$ & 4/10 (40.0) & & & \\
\hline & Present & $21 / 119(17.6)$ & $98 / 119(82.4)$ & $7.00(1.82-27.00)$ & $<0.01$ & $6.60(1.65-26.39)^{\star \star}$ \\
\hline \multirow[t]{2}{*}{ Chest Pain } & Absent & 24/125 (19.2) & $101 / 125$ (80.8) & & & \\
\hline & Present & $3 / 4(75.0)$ & $1 / 4(25.0)$ & $0.08(0.01-0.80)$ & 0.03 & $0.09(0.01-0.96)^{\star}$ \\
\hline \multirow[t]{2}{*}{ Conjunctivitis } & Absent & 23/123 (18.7) & 100/123 (81.3) & & & \\
\hline & Present & 4/6 (66.7) & 2/6 (33.3) & $0.12(0.02-0.67)$ & 0.02 & - \\
\hline \multirow[t]{2}{*}{ Cough } & Absent & 6/17 (35.3) & $11 / 17(64.7)$ & & & \\
\hline & Present & 21/112 (18.8) & $91 / 112$ (81.3) & $2.36(0.79-7.12)$ & 0.13 & - \\
\hline \multirow[t]{6}{*}{ Nu. of Typical Symptoms ARI } & 1 & 4/9 (44.4) & 5/9 (55.6) & 1.04 (0.60-1.79) & 0.89 & - \\
\hline & 2 & $7 / 25(28.0)$ & 18/25 (72.0) & & & \\
\hline & 3 & 12/87 (13.8) & 75/87 (86.2) & & & \\
\hline & 4 & 2/6 (33.3) & 4/6 (66.7) & & & \\
\hline & 5 & 1/1 (100.0) & 0/1 (0.0) & & & \\
\hline & 7 & $1 / 1$ (100.0) & 0/1 (0.0) & & & \\
\hline
\end{tabular}

COR, crude odds ratio; $A O R$, adjusted odds ratio; OR, odds ratio; $\mathrm{Cl}$, confidence interval. * $p<0.05$; ** $p<0.01$.

of ADV infections in the female group (14.5\%), although no statistically significant differences were observed (Table 1).

Sampling was performed in three different periods along 2019 (January, May, and November) in order to identify possible seasonal distribution of this collection of pathogens. The highest sample positive rate was detected in November (89.6\%), followed by May (78.3\%) and January (65.7\%; Table 1). Out of the 17 pathogens detected, four showed statistically significant differences among the three sampling periods, being FluA H3,
FluB and RSV most frequent in November and hMPV in May (Table 1).

Only two bacterial pathogens were found in our study: $C$. pneumoniae was detected in May and November (4.3\%, 2/46; $2.1 \%, 1 / 48$, respectively), while $M$. pneumoniae only in May $(2.2 \%, 1 / 46)$, all of them in low frequency.

The association between clinical presentation and ARI was also evaluated (Table 3). The bivariable analysis revealed that the days from the symptom onset, the presence of three or more 
TABLE 4 | Risk factors for ARI.

\begin{tabular}{|c|c|c|c|c|c|c|}
\hline Risk factors & & ARI negative -/n (\%) & ARI positive+/n (\%) & OR (95\% Cl) & $p$-value & AOR (95\% Cl) \\
\hline \multirow[t]{2}{*}{ Age } & $<1$ & $9 / 60(15.0)$ & $51 / 60(85.0)$ & & & \\
\hline & $1-4$ & 18/69 (26.1) & $51 / 69$ (73.9) & $0.50(0.20-1.22)$ & 0.13 & $\mathrm{n} / \mathrm{a}$ \\
\hline \multirow[t]{3}{*}{ Household crowding } & $<4$ & 0/14 (0.0) & 14/14 (100.0) & $\mathrm{n} / \mathrm{a}$ & 0.02 & \\
\hline & $4-5$ & 19/64 (29.7) & 45/64 (70.3) & & & \\
\hline & $>5$ & 8/51 (15.7) & 43/51 (84.3) & & & \\
\hline \multirow[t]{4}{*}{ Householder studies } & None & 0/7 (0.0) & $7 / 7(100.0)$ & $\mathrm{n} / \mathrm{a}$ & 0.05 & \\
\hline & Basic & 8/29 (27.6) & 21/29 (72.4) & & & \\
\hline & Secondary & $10 / 68(14.7)$ & 58/68 (85.3) & & & \\
\hline & Superior & $9 / 25(36.0)$ & $16 / 25(64.0)$ & & & \\
\hline \multirow[t]{4}{*}{ Householder income } & $<15,000 \$$ & $5 / 24(20.8)$ & 19/24 (79.2) & & 0.16 & \\
\hline & $15,000 \$-20,000 \$$ & $8 / 45$ (17.8) & $37 / 45$ (82.2) & $1.21(0.35-4.234)$ & 0.76 & - \\
\hline & $20,000 \$-40,000 \$$ & $3 / 28(10.7)$ & 25/28 (89.3) & $2.19(0.47-10.34)$ & 0.32 & - \\
\hline & $>40,000 \$$ & 11/32 (34.4) & 21/32 (89.7) & $0.50(0.15-1.71)$ & 0.27 & - \\
\hline \multirow[t]{3}{*}{ Residence regime } & Owner & $14 / 55(25.5)$ & $41 / 55(74.5)$ & & 0.17 & \\
\hline & Rent & $9 / 35(25.7)$ & 26/35 (74.3) & $0.99(0.37-2.61)$ & 0.98 & - \\
\hline & With other relatives & 4/39 (10.3) & 35/39 (89.7) & $2.99(0.90-9.91)$ & 0.07 & - \\
\hline \multirow{3}{*}{$\begin{array}{l}\text { Nu. of children }<5 \text { years old that } \\
\text { sleeps with an adult }\end{array}$} & 0 children's & $7 / 11(63.6)$ & $4 / 11(36.4)$ & & $<0.01$ & \\
\hline & 1 child & $9 / 85(25.7)$ & 26/85 (74.3) & $8.17(2.12-31.48)$ & $<0.01$ & $8.17(2.12-31.48)^{\star \star}$ \\
\hline & $>1$ child & 4/33 (10.3) & 35/33 (89.7) & $9.80(2.07-46.35)$ & $<0.01$ & $9.80(2.07-46.35)^{\star \star}$ \\
\hline \multirow[t]{2}{*}{ Presence of domestic animals } & No & 20/77 (26.0) & $57 / 77(74.0)$ & & & \\
\hline & Yes & $7 / 52(13.5)$ & 45/52 (86.5) & $2.26(0.88-5.81)$ & 0.09 & - \\
\hline
\end{tabular}

COR, crude odds ratio; AOR, adjusted odds ratio; OR, odds ratio; $\mathrm{Cl}$, confidence interval. ${ }^{\star *} \mathrm{p}<0.01, \mathrm{n} / \mathrm{a}$ : not applicable.

typical symptoms of ARI, and particularly the presence of nasal obstruction, chest pain, conjunctivitis, or cough, were variables with a $p<0.2$, and therefore were included in the multivariable logistic regression model. The forward stepwise binary logistic regression model accounted for $14.5 \%$ (Nagelkerke $R^{2}=0.145$ ) of the variance in prevalence. The presence of nasal obstruction and chest pain were significantly associated with ARI among children $<5$ years in the final model. The adjusted odds revealed children presenting nasal obstruction had higher risk of ARI (AOR: 6.6, $95 \%$ CI: $1.65,26.39)$, but chest pain was negatively associated with the detection of any of the pathogens of FilmArray RP2plus (AOR: 0.09, 95\% CI: 0.01, 0.96).

\section{Socio-Demographic Risk Factors for ARI}

Information regarding several socio-demographic factors was also collected for all patients included in this study. To determine their association with ARI, the proportion of children with each potential risk factor were compared in ARI positive and negative groups (Table 4). The bivariable analysis revealed that age, household crowding, householder studies, householder income, residence regime, number of children $<5$ years old that sleeps with an adult and presence of domestic animals were variables with a $p<0.2$, therefore were included in the multivariable logistic regression model.

Forward stepwise binary logistic regression models examined factors associated with ARI obtaining a model for the prevalence of ARI accounting for $12.4 \%$ (Nagelkerke $R^{2}=0.124$ ) of the variance in prevalence. In the final model, solely the number of children $<5$ years old sleeping in the same room with an adult was significantly associated with ARI. Thus, children $<5$ years old sharing the bedroom with an adult increased significantly their risk of ARI (OR: 8.17, 95\% CI: 2.12, 31.48) compared to those living in households where no children shared the bedroom with adults. This odds ratio was even higher (OR: 9.8, 95\% CI: 2.07, 46.35) when more than one child shared the same bedroom with an adult (Table 4). Interestingly, other factors such as household crowding, family income or the level of studies of the head of the family did not increase the risk of ARI among children $<5$ years old in our study.

\section{DISCUSSION}

To the best of our knowledge, this study is the first to investigate the role of 21 respiratory pathogens in children $<5$ years attended at the pediatrics service at the Hospital Dr. Agostinho Neto (HAN) in Praia city, Santiago Island, Archipelago of Cabo Verde with suspected ARI. This study reveals the pathogen profile that causes ARI in children $<5$ years and describes some clinical and socio-demographic factors associated with these infections. Our results are relevant toward the design and implementation of control programs and the optimal utilization of scarce resources for the most effective preventive, early management strategies, aiming to reduce the rate of morbidity and mortality by ARI in Cabo Verde.

Our results show a high infection rate (\%) in the population included in our study, in line with similar studies performed in 
different locations worldwide. For example, in Naples province (Southern Italy) the rate of ARI in children $<5$ years was $78.0 \%$ (25) and in Lusaka province in Zambia was 76.8\% (28), however studies in Malaysia and Ghana revealed much lower infection rates $(29,30)$. The variations in the published results can be explained by the differences in socio-economic factors, geographic and climatic differences, enrollment criteria, as well as the efficiency of local health care systems in different countries and patients' age $(7,9,25)$. Nevertheless, authors attribute testing platforms an important factor for the high rate and diversity of pathogens to be detected, due to the sensitivity and specificity of the testing platforms $(9,31)$.

In our data, viruses are the main causative agents of ARI in children $<5$ years with suspected ARI $(76.7 \%$ of all reported cases), with HRV/EV, FluA H3 and RSV being the most prevalent. The overall prevalence is comparable to previous studies done in other areas, like Naples $(25)$, China $(8,18)$, in three geographically distinct U.S. sites (26) and in Greece (32). All these highly prevalent viruses are usually associated with upper and lower respiratory tract infections to severe respiratory illness in infants, including bronchiolitis, pneumonia, wheezing, and are a leading cause of hospitalization in pediatrics emergency departments $(18,25,32,33)$. Cabo Verde does not have a surveillance system for agents that cause ARI, despite the high prevalence of reported cases of ARI in children $<5$ years. Therefore, our findings become important, because some of these viruses have also been described as responsible for infections in other organs such as heart and central nervous system (33), and these viruses can play a more significant role than originally thought. So additional studies describing our serotypes and/or variants will help to further understand how much these viruses contribute to severity of disease in this community and their role in infection dynamics at national and international level.

Co-infection with multiple respiratory pathogens was detected in $20.6 \%$ of the positive specimens tested by FilmArray ${ }^{\circledR}$ Respiratory Panel v.2.0 Plus in our study, in line with some reports in the world $(28,34)$. Interestingly, studies in patients with ARI suggest that pediatric patients are more likely to be infected by multiple pathogens than adults (8). We showed that HRV/EV were the most frequent pathogens detected in co-infection in children with suspected ARI, being $\mathrm{HRV} / \mathrm{EV}+\mathrm{ADV}$ the most frequent combination which is in line with reported data in asymptomatic and symptomatic children $(8,25,32,35)$. Although the reason behind co-infection between $\mathrm{HRV} / \mathrm{EV}$ and other pathogens that cause ARI is unclear, the infection mechanisms used by this virus have been suggested as important factors that facilitate connection, translation and persistence of other viruses and bacteria (36).

Variations in the rates of influenza infections have been reported in several studies in different age groups, especially in children $<5$ years $(37-40)$. In our study, FluA H3 was the only subtype of influenza virus showing a statistically significant difference by age, being more prevalent in children aged between 1 and 4 years than $<1$ year $(p=0.04)$. To explain this variation, the interaction between age and susceptibility to influenza infection have been suggested, as the immunity against influenza infection probably differs between age groups due to previous exposure to different influenza subtypes (41).

Interestingly, adenovirus was more common in female children than male children. In contrast, additional studies showed that male children are more susceptible to adenoviruses infections (42). To date, no study involving children $<5$ years with suspected ARI has reported a relationship between positive cases of $\mathrm{ADV}$ and sex $(13,42-45)$, and the risk factors for adenovirus respiratory infection in children are controversial (44). However, adenoviruses are considered important causative agents of ARI in children (13), accounting for $2-5 \%$ of the overall respiratory infections and $4-10 \%$ of the pneumonia $(43,45,46)$.

Statistical differences in the positivity rates of ARI were noted across seasons in our study, with November and May being the months with highest positive rates of ARI. Among the pathogens tested, only hMPV, FluA H3, Flu B, and RSV showed a distinct seasonality, in line with other studies from Zambia,Kenya and Brazil $(12,13,34,47,48)$. Seasonal fluctuations in the incidence of ARI caused by viruses/bacteria are associated with the climatic characteristics of the study areas $(25,49,50)$. As an example, in tropical areas, more than one period of viral/bacterial activity can occur during the year, with peaks during the mild winter and rainy season; in contrast, in the temperate areas, the peaks occur mainly in winter $(12,13,47,51,52)$. This phenomenon has been very well studied in southern Brazil, where researchers have found that adenoviruses circulate year-round, particularly in the summer (13), PIV 1 circulates in the fall, PIV 2 during fall and spring, and PIV 3 during spring (47). In contrast, influenza A and B circulate mainly in winter (12). Additional studies will be necessary to understand the seasonality of ARI caused by viruses/bacteria in Cabo Verde.

Atypical respiratory pathogens Chlamydia pneumoniae, Mycoplasma pneumoniae and Legionella pneumophila are recognized as a significant cause of ARI (53-55). Although C. pneumonia and M. pneumoniae were only found in low frequency in this study, it is important to monitor them in this community because previous studies demonstrated the implication of these bacteria in community-acquired pneumonia (CAP), acute exacerbations of chronic bronchitis, asthma, and less frequently, upper respiratory-tract infections $(53,56,57)$.

Several Coronavirus (CoVs) subtypes have been described as causative agents of acute respiratory infections in humans since the mid-1960s (58). Four endemic CoVs subtypes were described in our study, CoV-229E, CoV-OC63, CoV-HL63, and $\mathrm{CoV}-\mathrm{HKU} 1$, but all in low frequencies. It is well known that $\mathrm{CoVs}$ are implicated in cases of severe respiratory tract infections worldwide, and despite the growing interest, important gaps in the knowledge about CoVs remain (58-60).

Different clinical presentations have been associated with ARI worldwide (61-63). Despite the association found between several symptoms and ARI in our study, only the presence of nasal obstruction significantly increased the risk of ARI caused by any of the described pathogens. Evidence from other studies indicated an association between fever and an increased risk of severe respiratory infection $(61,64)$, but not for chest pain, cough, nasal obstruction and conjunctivitis (61, 65). Interestingly, children reporting chest pain had significantly decreased odds 
of ARI in or study. This finding can be explained by the fact that chest pain have been associated with several other etiologies, apart from ARI (66-68).

This study also described the social and demographic factors associated with ARI caused by any of the pathogens included in Film Array RP2 plus. In our data, only having one or more children sharing the bedroom with an adult increased significantly the risk among children $<5$ years attending the pediatrics service of Dr. Agostinho Neto Hospital in Praia city, Santiago Island, Cabo Verde with suspected ARI. Interestingly, other variables generally described as risks factors for ARI in children $<5$ years worldwide, such as age and household crowding, did not show that association in our model (69-71). In our study, the prevalence of ARI was equally distributed among the age groups, but additional studies show that children under 1 year of age are more susceptible to ARI compared to those aged $>1$ years $(70,71)$. Increased ARI among lower age children might be due to less developed immunity (72).

In conclusion, 17 different respiratory pathogens were detected as etiological agents for ARI in children $<5$ years attending at the pediatrics service at the Dr. Agostinho Neto Hospital (HAN) in Praia city, Santiago Island, Cabo Verde. Viruses were the main etiologic agents of ARI in this population, being HRV/EV, FluA H3, and RSV the most prevalent agents detected. Besides, some socio-demographic data and clinical symptoms are described as risk factors for ARI in children $<5$ years old. The data addresses the lack of studies on respiratory tract infections in Cabo Verde and highlights the need of more studies involving other health services in the country. However, these findings may be useful at national and international level. Moreover, future efforts to reduce the impact of ARIs will depend on the commitment of competent organs to mobilize resources to finance and implement programs to introduce vaccines, particularly in this age group where most of the morbidity and mortality is associated with ARI.

\section{DATA AVAILABILITY STATEMENT}

The original contributions presented in the study are included in the article/supplementary material, further inquiries can be directed to the corresponding author.

\section{REFERENCES}

1. Filho EBS, Silva AL, Santos AO, Dall'acqua DSV SL. Infecções respiratórias de importância clínica : uma revisão sistemática review. Revita FIMCA. (2017) 4, 7-16. doi: 10.37157/fimca.v4i1.5

2. Azevedo JV, Santos CA, Alves TL, Azevedo PV, Olinda RA. Influência do clima na incidência de infecção respiratória aguda em crianças nos Municípios de Campina Grande e Monteiro, Paraíba, Brasil. Rev Bras Meteorol. (2015) 30:467-77. doi: 10.1590/0102-778620140066

3. Babady NE, England MR, Smith LJ, He T, Wijetunge S, Chamberland RR, et al. Multicenter evaluation of the ePlex respiratory pathogen panel for the detection of viral and bacterial respiratory tract pathogens in nasopharyngeal swabs. J Clin Microbiol. (2018) 56: 01658. doi: 10.1128/JCM.01658-17

\section{ETHICS STATEMENT}

The studies involving human participants were reviewed and approved by National Health Research Ethics Committee of Cabo Verde (CNEPS) (deliberation no. 72/2018). Written informed consent to participate in this study was provided by the participants' legal guardian/next of kin.

\section{AUTHOR CONTRIBUTIONS}

EC and IIMdP-A designed, supervised, oversaw the study implementation, and revised the manuscript. WC designed, implement the study, collected the data, interpreted the data, and wrote the manuscript. RD-G conducted the analysis of the data and revised the manuscript. MS and CA worked in sample and data collection at the pediatric service of Dr. Agostinho Neto Hospital. BV revised the manuscript. All authors have contributed substantially to the study, read, and approved the final manuscript.

\section{FUNDING}

This study was funded by Fundación Canaria para el Control de Enfermedades Tropicales (FUNCCET), Cabildo de Tenerife Proyectos de Cooperación e Investigación and Instituto Universitario de Enfermedades Tropicales y Salud Publica de Canarias en Universidad de La Laguna (IUETSPC/ULL) Tenerife, Islas Canarias, Spain.

\section{ACKNOWLEDGMENTS}

We gratefully thank to all patients who participated in this study, the Ministry of Health and Social Security of Cabo Verde and Dr. Agostinho Neto Hospital (HAN) for the authorization to carry out this work, as well as National Institute of Public Health of Cabo Verde (INSP) for storing the samples. We thank the pediatric sector of HAN, all the physicians, nurses and other workers, for their support and contribution throughout the work. We thank Cabildo de Tenerife, Fundación Canaria para el Control de Enfermedades Tropicales (FUNCCET), and Instituto Universitario de Enfermedades Tropicales y Salud Pública de Canarias en Universidad de La Laguna (IUETSPC/ULL) Tenerife, Islas Canarias for providing experimental resources.

4. Heikkinen T, Jarvinen A. Common cold_lancet. Lancer. (2003) 361:519. doi: 10.1016/S0140-6736(03)12162-9

5. Marcone DN, Carballal G, Ricarte C, Echavarria M. Automatizado de PCR múltiples (FilmArray) y su comparación con. RE Argent Microbiol Argent Microbiol. (2015) 47:29-35. doi: 10.1016/j.ram.2014.12.003

6. Bhuyan GS, Hossain MA, Sarker SK, Hahat A, Islamt MT, Haque TN, et al. Bacterial and viral pathogen spectra of acute respiratory infections in under-5 children in hospital settings in Dhaka city. PLoS ONE. (2017) 12:e0174488. doi: 10.1371/journal.pone.0174488

7. Lagare A, Mainassara HB, Issaka B, Sidiki A, Tempia S. Viral and bacterial etiology of severe acute respiratory illness among children < 5 years of age without influenza in Niger. BMC Infect Dis. (2015) 15:515. doi: 10.1186/s12879-015-1251-y 
8. Li J, Tao Y, Tang M, Du B, Xia Y, Mo X, et al. Rapid detection of respiratory organisms with the FilmArray respiratory panel in a large children 's hospital in China. BMC Infect Dis. (2018) 18:510. doi: 10.1186/s12879-018-3429-6

9. Kenmoe S, Tchendjou P, Vernet M-A, Moyo-Tetang S, Mossus T, NjankouoRipa M, et al. Viral etiology of severe acute respiratory infections in hospitalized children in Cameroon, 2011-2013. Influ Other Respir Virus. (2016) 10:386-93. doi: 10.1111/irv.12391

10. Peeri NC, Shrestha N, Rahman MS, Zaki R, Tan Z, Bibi S, et al. The SARS, MERS and novel coronavirus (COVID-19) epidemics, the newest and biggest global health threats: what lessons have we learned? Int J Epidemiol. (2020) 49:717-26. doi: 10.1093/ije/dyaa033

11. Lagare. Molecular detection of respiratory pathogens among children aged younger than 5 years hospitalized with febrile acute respiratory infections: a prospective hospital-based observational study in Niamey, Niger. Heal Sci Rep. (2019) 2:137. doi: 10.1002/hsr2.137

12. Duarte MB, Gregianini TS, Martins LG, Veiga ABG. Epidemiology of influenza B infection in the state of Rio Grande do Sul, Brazil, from 2003 to (2019). J Med Virol. (2021) 93:4756-62. doi: 10.1002/jmv.26822

13. Pscheidt VM, Gregianini TS, Martins LG, Veiga ABG da. Epidemiology of human adenovirus associated with respiratory infection in southern Brazil. Rev Med Virol. (2021) 31:e2189. doi: 10.1002/rmv.2189

14. Rowlinson E, Dueger E, Mansour A, Azzazy N, Mansour H, Peters L, et al. Incidence and etiology of hospitalized acute respiratory infections in the Egyptian Delta. Influenza Other Respir Viruses. (2017) 11:2332. doi: 10.1111/irv.12409

15. Fitzner J, Qasmieh S, Mounts W, Alexander B, Besselaar T, Briand $\mathrm{S}$, et al. Revision of clinical case definitions : influenza-like illness and severe acute respiratory infection. Policy Pratct. (2018) 96:1228. doi: 10.2471/BLT.17.194514

16. Tazinya AA, Halle-Ekane GE, Mbuagbaw LT, Abanda M, Atashili J, Obama MaT. Risk factors for acute respiratory infections in children under five years attending the Bamenda Regional Hospital in Cameroon. BMC Pulm Med. (2018) 18:7. doi: 10.1186/s12890-018-0579-7

17. WHO. World Health Statistics. Geneva (2010). 273 p.

18. Chen J, Hu P, Zhou T, Zheng T, Zhou L, Jiang C, et al. Epidemiology and clinical characteristics of acute respiratory tract infections among hospitalized infants and young children in. BMC Pediatr. (2018) 18:216. doi: 10.1186/s12887-018-1203-y

19. Projecções Demográficas de Cabo verde. Instituto Nacional de Estatística (INE). Praia (2010). Available online at: https://ine.cv/

20. Plano Nacional de Desenvolvimento Sanitário 2017-2021, Vol. I. Ministério da Saúde e da Segurança Social de Cabo Verde. Praia (2017). p. 109

21. WHO. Cabo Verde: WHO Statistical Profile. Available online at: http://www. who.int/gho/en// (2015).

22. Relatório Estatístico 2018. Ministério da Saúde e da Segurança Social de Cabo Verde. Praia (2019). p. 164

23. Dia $\mathrm{N}$, Ndiaye $\mathrm{MN}$, Monteiro $\mathrm{M}$ de L, Koivogui L, Bara MO, Diop OM. A subregional analysis of epidemiologic and genetic characteristics of influenza a (H1N1) pdm09 in Africa : Senegal, Cape Verde, Mauritania, and Guinea, 2009-2010. Am Soc Trop Med Hyg. (2013) 88:946-53. doi: 10.4269/ajtmh.12-0401

24. Baden LR, Drazen JM, Kritek PA, Curfman GD, Morrissey S, Campion EW. H1N1 influenza a disease - information for health professionals implications of the emergence of a novel H1 influenza virus. N Engl J Med. (2009) 360:2667-8. doi: 10.1056/NEJMe0903992

25. Botti C, Micillo A, Ricci G, Russo A, Denisco A, Cantile M, et al. Characterization of respiratory infection viruses in hospitalized children from Naples province in Southern Italy. Exp Ther Med. (2018) 15:48059. doi: 10.3892/etm.2018.6061

26. Mckinley K, Jones M, Holmberg K. Multicenter Evaluation of BioFire FilmArray Respiratory Panel 2 for Detection of Viruses and Bacteria in Nasopharyngeal Swab Samples. J Clin Microbiol. (2018) 56:1-11. doi: 10.1128/JCM.01945-17

27. Kaku N, Hashiguchi K, Iwanaga Y, Akamatsu N, Matsuda J, Kosai K, et al. Evaluation of FilmArray respiratory panel multiplex polymerase chain reaction assay for detection of pathogens in adult outpatients with acute respiratory tract infection. J Infect Chemother. (2018) 24:734-8. doi: 10.1016/j.jiac.2018.05.006
28. Hoffmann J, Rabezanahary H, Randriamarotia M, Ratsmbasoa A, Najjar J, Vernet $\mathrm{G}$, et al. Viral and atypical bacterial etiology of acute respiratory infections in children under 5 years old living in a rural tropical area of madagascar. PLoS ONE. (2012) 7:e43666. doi: 10.1371/journal.pone.0043666

29. Khor C-S, Sam I-C, Hooi P-S, Quek K-F, Chan Y-F. Epidemiology and seasonality of respiratory viral infections in hospitalized children in Kuala Lumpur, Malaysia: a retrospective study of 27 years. BMC Pediatr. (2012) 12:32. doi: 10.1186/1471-2431-12-32

30. Kwofie TB, Anane YA, Nkrumah B, Annan A, Nguah SB, Owusu M. Respiratory viruses in children hospitalized for acute lower respiratory tract infection in Ghana. Virol J. (2012) 9:78. doi: 10.1186/1743-422X-9-78

31. Bezerra PGM, Britto MCA, Correia JB, Duarte $M$ do CMB, Fonceca $\mathrm{AM}$, Rose $\mathrm{K}$, et al. Viral and atypical bacterial detection in acute respiratory infection in children under five years. PLoS ONE. (2011) 6:e18928. doi: 10.1371/journal.pone.0018928

32. Tsagarakis NJ, Sideri A, Makridis P, Triantafyllou A, Stamoulakatou A, Papadogeorgaki E. Age-related prevalence of common upper respiratory pathogens, based on the application of the FilmArray Respiratory panel in a tertiary hospital in Greece. Medicine (Baltimore). (2018) 97:e10903. doi: 10.1097/MD.0000000000010903

33. Krammer F, Smith GJD, Fouchier RAM, Peiris M, Kedzierska K, Doherty PC, et al. Influenza. Nat Rev Dis Prim. (2018) 4:3. doi: 10.1038/s41572-018-0002-y

34. Simusika P, Bateman AC, Theo A, Kwenda G, Mfula C, Chentulo E. Identification of viral and bacterial pathogens from hospitalized children with severe acute respiratory illness in Lusaka, Zambia, 2011-2012 : a crosssectional study. BMC Infect Dis. (2015) 15:52. doi: 10.1186/s12879-015-0779-1

35. Wong-Chew RM, García-León ML, Noyola DE, Perez LF, Meza JG, VilaseñorSierra A, et al. Respiratory viruses detected in Mexican children younger than 5 years old with community-acquired pneumonia : a national multicenter. Int J Infect Dis. (2017) 62:32-8. doi: 10.1016/j.ijid.2017.06.020

36. To KKW, Yip CCY, Yuen K-Y. Rhinovirus - From bench to bedside. J Formos Med Assoc. (2017) 116:496-504. doi: 10.1016/j.jfma.2017.04.009

37. Luniewska K, Szymański K, Hallmann-Szelińska E, Kowalczyk D, Sałamatin $\mathrm{R}$, Masny A, et al. Infections caused by influenza viruses among children in Poland during the 2017/18 epidemic season. Adv Exp Med Biol Clin Exp Biomed. (2019) 7:97-102. doi: 10.1007/5584_2019 393

38. Odun-Ayo F, Odaibo G, Olaleye D. Influenza virus A (H1 and H3) and B cocirculation among patient presenting with acute respiratory tract infection in Ibadan, Nigeria. Afr Health Sci. (2018) 18:1134-43. doi: 10.4314/ahs.v18i4.34

39. Turbelin C, Souty C, Pelat C, Hanslik T, Sarazin M, Blanchon T, et al. Age Distribution of influenza like illness cases during post-pandemic $\mathrm{A}(\mathrm{H} 3 \mathrm{~N} 2)$ : comparison with the twelve previous seasons, in France. PLoS ONE. (2013) 8:e65919. doi: 10.1371/journal.pone.0065919

40. Wong KC, Luscombe GM, Hawke C. Influenza infections in Australia 20092015: Is there a combined effect of age and sex on susceptibility to virus subtypes? BMC Infect Dis. (2019) 19:42. doi: 10.1186/s12879-019-3681-4

41. J. Beauté J, Zucs P, Korsun N, Bragstad K, Enouf V, Kossyvakis A, et al. Age-specific differences in influenza virus type and subtype distribution in the 2012/2013 season in 12 European countries. Epidemiol Infect. (2015) 143:2950-8. doi: 10.1017/S0950268814003422

42. Bakir J, Juárez MDV, Lución MF, Areso MS, Viegas M, Bochemist, et al. Clinical and epidemiological study of acute lower respiratory tract infections caused by adenovirus in hospitalized children. Nineteen years of active epidemiological surveillance. Arch Argent Pediatr. (2020) 118:193201. doi: 10.5546/aap.2020.eng.193

43. Liu C, Xiao Y, Zhang J, Ren L, Li J, Xie Z, et al. Adenovirus infection in children with acute lower respiratory tract infections in Beijing, China, 2007 to (2012). BMC Infect Dis. (2015) 15:408. doi: 10.1186/s12879-015-1126-2

44. Wu P-Q, Zeng S-Q, Yin G-Q, Huang J-J, Xie Z-W, Lu G, et al. Clinical manifestations and risk factors of adenovirus respiratory infection in hospitalized children in Guangzhou, China during the 2011-2014 period. Medicine (Baltimore). (2020) 99:4. doi: 10.1097/MD.0000000000018584

45. Zhao MC, Guo YH, Qiu FZ, Wang L, Yang S, Feng ZS, et al. Molecular and clinical characterization of human adenovirus associated with acute respiratory tract infection in hospitalized children. J Clin Virol. (2020) 123:104254. doi: 10.1016/j.jcv.2019.104254

46. Chau S-K, Lee S-L, Peiris MJS, Chan K-H, Chan E, Wong W, et al. Adenovirus respiratory infection in hospitalized children in Hong Kong: Serotype-clinical 
syndrome association and risk factors for lower respiratory tract infection. Eur J Pediatr. (2014) 173:291-301. doi: 10.1007/s00431-013-2127-z

47. Gregianini TS, Seadi CF, Zavarize Neto LD, Martins LG, Muller GC, Straliotto SM, et al. A 28-year study of human parainfluenza in Rio Grande do Sul, Southern Brazil. J Med Virol. (2019) 91:1423-31. doi: 10.1002/jmv.25459

48. Breiman RF, Cosmas L, Njenga MK, Williamson J, Mott JA, Katz MA, et al. Severe acute respiratory infection in children in a densely populated urban slum in Kenya, 2007-2011. BCM Infect Dis. (2015) 15:95. doi: 10.1186/s12879-015-0827-x

49. S. Caini S, Mora D, Olmedo M, Becerra MA, Mejía M, Pacurucu MC, et al. The epidemiology and severity of respiratory viral infections in a tropical country: Ecuador, 2009-2016 Saverio. J Infect Public Heath. (2020) 12:35763. doi: 10.1016/j.jiph.2018.12.003

50. Çiçek C, Arslan A, Karakuş HS, Yalaz M, Saz EU, Pullukçu H, et al. Prevalence and seasonal distribution of respiratory viruses in patients with acute respiratory tract infections, 2002-2014 [Akut Solunum Yolu Enfeksiyonu Olan Hastalarda Solunum Viruslarinin Prevalansi ve Mevsimsel Da?ilimi, 2002-2014]. Mikrobiyol Bul. (2015) 49:188-200. doi: 10.5578/mb.9024

51. Alonso WJ, Viboud C, Simonsen L, Hirano EW, Daufenbach LZ, Miller MA. Seasonality of influenza in Brazil: a traveling wave from the amazon to the subtropics. Am J Epidemiol. (2007) 165:1434-42. doi: 10.1093/aje/kwm012

52. Chit MW, Yang L, King PC, Leung GM, Chan KH, Guan Y, et al. Influenza-associated hospitalization in a subtropical city. PLoS Med. (2006) 3:e121. doi: 10.1371/journal.pmed.0030121

53. Blasi F. Atypical pathogens and respiratory tract infections. Eur Respir J. (2004) 24:171-81. doi: 10.1183/09031936.04.00135703

54. Choroszy-Król I, Frej-Madrzak M, Hober M, Sarowska J, Jama-kmiecik A. Infections Caused by Chlamydophila pneumoniae. Adv Clin Exp Med. (2014) 23:123-6. doi: 10.17219/acem/37035

55. Esposito S, Blasi F, Bellini F, Allegra L, Principi N, Group S. Mycoplasma pneumoniae and Chlamydia pneumoniae infections in children with pneumonia. Eur Respir J. (2001) 17:2415. doi: 10.1183/09031936.01.17202410

56. Chen H, Weng H, Lin M, He P, Li Y, Xie Q, et al. The clinical significance of filmarray respiratory panel in diagnosing community-acquired pneumonia. Biomed Res Int. (2017) 2017:7320859. doi: 10.1155/2017/7320859

57. Johnston SL, Martin RJ. Pulmonary perspective chlamydophila pneumoniae and mycoplasma pneumoniae a role in asthma pathogenesis? Am J Respir Crit Care Med. (2005) 172:1078-89. doi: 10.1164/rccm.200412-1743PP

58. Trombetta H, Faggion HZ, Leotte J, Nogueira MB, Vidal LRR, Raboni SM. Human coronavirus and severe acute respiratory infection in Southern Brazil. Pathog Glob Health. (2016) 110:1-6. doi: 10.1080/20477724.2016.1181294

59. Lusignan S, Dorward J, Correa A, Jones N, Akinyemi O, Amirthalingam G, et al. Risk factors for SARS-CoV-2 among patients in the Oxford Royal College of General Practitioners Research and Surveillance Centre primary care network : a cross-sectional study. Lancet Infect Dis. (2020) 20:103442. doi: 10.1016/S1473-3099(20)30371-6

60. Uddin SMI, Englund JA, Kuypers JY, Chu HY, Steinhoff MC, Khatry SK, et al. Burden and risk factors for coronavirus infections in infants in rural Nepal. Clin Infect Dis. (2018) 67:1507-14. doi: 10.1093/cid/ciy317

61. Atwell JE, Geoghegan S, Karron RA, Polack FP. Clinical predictors of critical lower respiratory tract illness due to respiratory syncytial virus in infants and children: data to inform case definitions for efficacy trials. J Infect Dis. (2016) 214:1712-6. doi: 10.1093/infdis/jiw447

62. Leung C. Risk factors for predicting mortality in elderly patients with COVID19: A review of clinical data in China. Mech Ageing Dev. (2020) 188:111255. doi: 10.1016/j.mad.2020.111255
63. Macedo SEC SEC, Menezes AMB, Albernaz E, Post P, Knorst M. Fatores de risco para internação por doença respiratória aguda em crianças até um ano de idade. Rev Saude Publica. (2007) 41:351-8. doi: 10.1590/S0034-89102007000300005

64. Yamamoto S, Yamazaki S, Shimizu T, Takeshima T, Fukuma S, Yamamoto $\mathrm{Y}$, et al. Body temperature at the emergency department as a predictor of mortality in patients with bacterial infection. Medicine (Baltimore). (2016) 95:e3628. doi: 10.1097/MD.0000000000003628

65. Amesty MA, Jorge L, Barrio A, Alió JL. COVID-19 disease and ophthalmology: an update. Ophthalmol Ther. (2020) 9:41526. doi: 10.1007/s40123-020-00260-y

66. Backus BE, Six AJ, Kelder JH, Gibler WB, Moll FL, Doevendans PA. et al. Risk scores for patients with chest pain: evaluation in the emergency depart. Curr Cardiol Rev. (2011). 7:2-8. doi: 10.2174/157340311795677662

67. Paichadze N, Afzal B, Zia N, Mujeeb R, Khan MM, Razzak JA. Characteristics of chest pain and its acute management in a low-middle income country: Analysis of emergency department surveillance data from Pakistan. BMC Emerg Med. (2015) 15(Suppl 2):S13. doi: 10.1186/1471-227X-15-S2-S13

68. Parsonage WA, Cullen L, Younger JF. The approach to patients with possible cardiac chest pain. Med J Aust. (2013) 199:30-4. doi: 10.5694/mja12.11171

69. Cox M, Rose L, Kalua K, Wildt G De, Bailey R, Hart J. The prevalence and risk factors for acute respiratory infections in children aged 0- - 59 months in rural Malawi : a cross- - sectional study. Influ Other Respir Viruses. (2017) 11:489-96. doi: 10.1111/irv.12481

70. Dagne H, Andualem Z, Dagnew B, Taddese AA. Acute respiratory infection and its associated factors among children under- five years attending pediatrics ward at University of Gondar Comprehensive Specialized Hospital, Northwest Ethiopia: institution-based cross-sectional study. BMC Pediatr. (2020) 20:93. doi: 10.1186/s12887-020-1997-2

71. Sonego M, Pellegrin MC, Becker G, Lazzerini M. Risk factors for mortality from acute lower respiratory infections (ALRI) in children under five years of age in low and middle- income countries : a systematic review and meta-analysis of observational studies. PLoS ONE. (2015) 10:e0116380. doi: 10.1371/journal.pone.0116380

72. Dickson A. Amugsi DA, Aborigo RA, Oduro AR, Asoala V, Awine T, et al. Socio-demographic and environmental determinants of infectious disease morbidity in children under 5 years in Ghana. Glob Heath Action. (2015) 8:29349. doi: 10.3402/gha.v8.29349

Conflict of Interest: The authors declare that the research was conducted in the absence of any commercial or financial relationships that could be construed as a potential conflict of interest.

Publisher's Note: All claims expressed in this article are solely those of the authors and do not necessarily represent those of their affiliated organizations, or those of the publisher, the editors and the reviewers. Any product that may be evaluated in this article, or claim that may be made by its manufacturer, is not guaranteed or endorsed by the publisher.

Copyright $\odot 2021$ Correia, Dorta-Guerra, Sanches, Almeida Semedo, Valladares, de Pina-Araújo and Carmelo. This is an open-access article distributed under the terms of the Creative Commons Attribution License (CC BY). The use, distribution or reproduction in other forums is permitted, provided the original author $(s)$ and the copyright owner(s) are credited and that the original publication in this journal is cited, in accordance with accepted academic practice. No use, distribution or reproduction is permitted which does not comply with these terms. 